\title{
EVALUATION OF WORLD RANKING, WEB VISIBILITY AND CONTENT ACCESSIBILITY OF QURAN WEB PORTALS
}

\author{
Shouket Ahmad Kouchay ${ }^{1}$,
}

\section{ABSTRACT}

The use of search engines is the most common way of finding the information. This means that less visible contents (for search engines) are increasingly difficult or even almost impossible to find. Thus, Web users are forced to accept alternative services or contents only because they are visible and offered to users by search engines.. Therefore, it is fundamental to assure that one's Web site will be indexed and, consequently, visible and accessible to as many Web users as possible. The websites are the most useful platform to disseminate Quran knowledge and information. The most important website that Muslims interact with is the Holy Quran websites. Higher quality websites tend to attract more links and rendered those websites as highly visible. In this study softwares like Seoquak, Alexa, AChecker is applied to evaluate the visibility and accessibility of Quran Web Portals/websites. Eight Quran Websites/WebPortals were investigated. It was found that the website Quranexplorer.com has drawn a Top traffic ranking among eight selected websites. It is futile to have a website that is difficult to access by users owing to non compliance with the Web Content Accessibility Guidelines.. The software like AChecker is able to examine the Al-Quran websites for barriers to accessibility. Applying AChecker to the 8 Quranic websites it was found that the website, namely the Altafsir.com top the list in terms of the most number of errors in their website.

Keywords: Web visibility, Quran websites, accessibility, Quran.

\footnotetext{
(") This article was submitted on: 16/10/2013 and accepted for publication on: 11/06/2014.

1 Dr. Shouket, College of Computer Engineering and Sciences- Salman Bin Abdul Aziz University-KSA, Email: sh.ahmad@sau.edu.sa
} 


\subsection{INTRODUCTION}

In recent years search engines have become an indispensable tool for information discovery. Billions of searches are performed by hundreds of millions of users around the world. ${ }^{1}$ The visibility of a web site in search engines is therefore an important metric that web site owners, competitors, researchers, and even users are interested in. The Web site must compete against thousands of other Web sites with the same or similar content, information, and even design and quality. If we wish to "win the battle," then we need to have an added value: We need to be found first. As noted by Wu and Davison, the "search engine is the door to the Web today.". 2

Web visibility is the appearance of web sites in search engines. Web visibility in search engine is an important factor to improve the presence on the web. If the web site gets high ranking in search engines it will attract more web traffic. well-designed site will not be successful if the potential users cannot find the site.

Web link analysis is method to evaluate the rate of a web site's connectivity on the world wide web. The number of links leading to the site is a measure of popularity and impact of a web site because the more links there are to a site, the higher the probability that the site will be visited, and therefore, the more potential impact the site will have within the scholarly community. ${ }^{3}$ Inbound link or Inlink is any link received by a web node (web page, directory, website, or top level domain) from another web node. ${ }^{4}$

The websites may also serve as a mechanism for conducting interactive communication since the format of communication can be any (or all) of text, audio, video and graphics. As these websites are around for quite sometimes already it is therefore appropriate to question on how effective are those websites. To get the desired results from this type of question it is imperative

1 ComScore. 61 billion searches conducted worldwide in August. www.comscore.com/press /release.asp?press=1802, 2008.

2 Wu, B., \& Davison, B.D. (2006, April). Undue influence: Eliminating the impact of link plagiarism on web search rankings. ACM SAC 2006. ACM 1-59593-108-2/06/0004. Dijon, France.

3 Vaughan, L., Thelwall, M. (2003), "Scholarly use of the web: what are the key inducers of links to journal websites?", Journal of the American Society for Information Science and Technology, Vol. 54 No.1, pp.29-38.

4 Wikipedia- Alexa Internet - http://en.wikipedia.org/wiki/Alexa_Internet. 
for a study to be conducted to address the issue. As Conway and Dorner pointed out " a party may be providing large amounts of information on its website, but if this information is difficult to find, its usefulness will be reduced. Likewise, a website may offer a high level of interactivity, but if a user cannot access the site it will count for little". ${ }^{1}$ A website should also communicate a message to its intended audience. ${ }^{2}$

On April 16, 2008, many users reported dramatic shifts in their Alexa rankings. Alexa confirmed this later in the day with an announcement that they had released an updated ranking system, claiming that they would now take into account more data sources "beyond Alexa Toolbar users. ${ }^{3}$

It is essential that the web be accessible to people with equal access and equal opportunity to all also with disabilities. The Accessibility can be defined as the quality of a web site that makes it possible for people to use it - to find it navigable and understandable - even when they are working under limiting conditions or constraints. ${ }^{4}$ It is estimated that between $15 \%$ and $30 \%$ of the total general people i.e. 750 million in the world have functional disability to use technology tools. ${ }^{5}$

Again in the coming days this figure will increase due to some factors e.g. as growing older, most people experience a decrease in vision, hearing, physical abilities, and cognitive abilities. ${ }^{6}$ Accessible web sites accommodate a wider range of users, increasing the number of people who can effectively use a website which will promote Website day by day.

In this paper softwares like Seoquak, Alexa, AChecker is applied to study the visibility and accessibility of Quran Web Portals/websites.

1 Conway, M., \& Dorner, D. (2004). An evaluation of New Zealand political party websites. Information Research, 9(4), paper 196.

2 Longe, Heather (2008) The art of web design. Techniques 83(3), p26-33.

3 Wikipedia- Alexa Internet - http://en.wikipedia.org/wiki/Alexa_Internet.

4 Shawn Lawton Henry, Web Accessibility: Web Standards and Regulatory Compliance.: Friends of Ed, 2006, ISBN: 1590596382.

5 Chartbook on Disability in the U.S. [Online]. http://www. infouse.com/disabilitydataldisabilityll_l.php.

6 (2001, July) Disability as a Function of Age. [Online]. http: //trace. wisc.edu/ docs/functionaging. 


\subsection{WEB VISIBILITY}

A website is a window into how an organization operates. In recent years, the Internet has experienced a boom as an information source. The use of search engines is the most common way of finding this information. This means that less visible contents (for search engines) are increasingly difficult or even almost impossible to find. Thus, Web users are forced to accept alternative services or contents only because they are visible and offered to users by search engines. If a organization's Web site is not visible, that organization is losing clients. Therefore, it is fundamental to assure that one's Web site will be indexed and, consequently, visible to as many web users as possible.

The first thing that any organization would like to tell the world of its presence is through its website. The better site can help the convergence of the goals of the users and the owner, the more successful the site will be. ${ }^{1}$

A valid indicator of site visibility and online stature would be the volume of web traffic to a given site. Higher quality websites tend to attract more links. It has also been shown that search engines generate a large proportion of web traffic and most modern search engine algorithms tend to return heavily-linked sites first. Using Alexa and Seoquak it is possible to gauge the volume of the web traffic for a particular website or web portal.

As Al-Quran is the book of knowledge and guidance and it is the main source of reference in Islam which contains general principles applicable for all times and places, it is expected that there would be a lot of websites devoted to AlQuran. Using the search engine Google a click with the word "Quran" on 22 May 2013 gives of 245000000 results.

The number of websites dedicated to deliver the messages in the Al-Quran would also be in the millions. However, it is pertinent to note that a website may offer the best resources on Al-Quran, but if a user cannot access the site its usefulness will be reduced. Why should they waste their time on anything that is confusing, slow or that doesn't satisfy their needs? ${ }^{2}$ A valid indicator of site visibility and online stature would be the volume of web traffic to a given website. Based on the search results it seems that there is a tremendous increase in the number of websites of Quran hosted in the Internet. Within the

1 Fan, Weiguo, Schaupp, L. C. and Krishen, A. (2006). Web site success metrics: Addressing the duality of goals. Communications of the ACM, 49(12), P114-117.

2 Nielsen, Jacob (2000) How to Conduct a Heuristic Evaluation. Retrieved from http://www.useit.com/papers/heuristic/heuristic evaluation.html on 20 November 2008. 
constraints of time and resources I have decided to select some of these Quran websites for analysis with Alexa and Seoquak.

The first website that was selected was the King Fahd Complex for the Printing of the Holy Qur'an Complex for the Printing of the Holy Qur'an. Using Alexa on 30 April 2013, Qurancomplex.org is ranked \#120,637 in the world. The site has attained a traffic rank of 5,199 among users in Saudi Arabia, where $22 \%$ of its audience is located. The other countries where it mostly visited are Egypt, UAE, Algeria, Morocco, France, Iran, United States. It is noted that the website was first registered on 27 August 2000. Roughly 25\% of visits to the site are referred by search engines. It also showed that the speed is slow with an average load time of 2.98 seconds. However it improved as its was 8.52 seconds in $2010 .{ }^{1}$ At the moment there are 1778 other websites that are linked to this website. Approximately $23 \%$ of visits to the site are referred by search engines.

The second selected website is quranflash.com. The website was first registered on December 28, 2006. Quranflash.com has a three-month global Alexa traffic rank of 37,814. This site has attained a traffic rank of 1,507 among users in Egypt, where about $21 \%$ of its audience is located, and the fraction of visits to this site referred by search engines is about $10 \%$. The other countries where it mostly visited are Libya, Kuwait, Saudi Arabia, Algeria, Sudan, UAE, Germany. There are 5176 inbound links received by this website from other websites. The website speed is average with a load time of 0.875 seconds. Roughly $10 \%$ of visits to the site are referred by search engines.

The third selected website is understandquran.com. The aim of the web portal is to to help users to learn and understand the Quran using easy, efficient, and effective techniques. The maintainers have put in a lot of good effort which is really useful for English, Urdu and Hindi speaking users. The website was first registered on September 04, 2001. Understandquran.com has a three-month global Alexa traffic rank of 198208 . Approximately $14 \%$ of visits to the site are referred by search engines, and roughly $52 \%$ of visits to the site consist of only one pageview (i.e., are bounces). The time spent in a typical visit to this site is roughly four minutes, with 60 seconds spent on each pageview.This site has attained a traffic rank of 10,511 in Pakistan, 101,509 in India and 195,060 in United States.There are 368 other websites that are linked to this website. The website speed is average with a load time of 2.268 seconds.

1 Ahmad Bakeri Abu Bakar (2010) Evaluating the Accessibility and Visibility of QuranWebsites, Information Technology (ITSim), 2010 International Symposium, Print ISBN: 978$1-4244-6715-0$. 
The fourth analysed website is Qtafsir.com that is wholly addressing the domain of tafsir of the Quran. There are a good number of this type of website available on the Internet.

Qtafsir.com is ranked \#( Number) 311,790 in the world according to the threemonth Alexa traffic rankings, and the site has a relatively good traffic rank in the city of Columbus $(\# 3,176)$. Search engines refer about $15 \%$ of visits to the site. While Qtafsir.com is ranked \#164,522 in the US, where 35\% of its visitors are located, it is also popular in India, where it is ranked \#140,567. The site's visitors view an average of 3.9 unique pages per day. The website was first registered on August 28, 2006. There are 371 other websites that are linked to this website. The website speed is average with a load time of 2.268 seconds.

The fifth selected web portal Quranexplorer.com was first registered on December 12, 2005. The chosen website has drawn a high traffic ranking. Using Alexa on 30 April 2013, Quranexplorer.com is ranked \#34,802in the world. Roughly $16 \%$ of visits to the site are referred by search engines, and while it is ranked \#27,589 in the US, where about $19 \%$ of its visitors are located, it is also popular in Kuwait, where it is ranked \#2,411. Quranexplorer.com is relatively popular among users in the city of Hitachi (where it is ranked \#121). The other countries where it mostly visited are Brune, Kuwait, Azerbaijan, Malaysia India, Qatar. There are 3549 other websites that are linked to this website. The website speed is average with a load time of 3.844 seconds.

The sixth selected website ATafsir.com was first registered on April 17, 2001. Altafsir.com is ranked \#152,402 in the world according to the three-month Alexa traffic rankings. Roughly $17 \%$ of visits to the site are referred by search engines. Compared with internet averages, the site appeals more to users who browse from school and home.The time spent in a typical visit to Altafsir.com is approximately seven minutes, with 63 seconds spent on each pageview. There are 1283 other websites that are linked to this website. The website speed is average with a load time of 2.897 seconds. The countries where it mostly visited are Jordon, Kuwait, UAE, Algeria, Egypt, UK, Turkey, USA.

The seventh selected website mp3quran.com was first registered on October 02, 2003. Mp3quran.com has a three-month global Alexa traffic rank of 4,650,656, and the site is based in the US. There are roughly 13 other websites that are linked to this website. The website speed is average with a load time of 1.385 seconds. The countries where it mostly visited are Egypt, Algeria, KSA, UK. Roughly $16 \%$ of visits to the site are referred by search engines. 
The eighth selected website Allahsquran.com was first registered on April 09, 2006. Allahsquran.com is ranked \#472,617 in the world according to the threemonth Alexa traffic rankings, and visitors to this site view 2.4 unique pages each day on average. It is relatively popular among users in the city of Tanta (where it is ranked \#546), and this site has attained a traffic rank of 13,114 among users in Egypt, where about 27\% of its audience is located. Visitors to website spend about 74 seconds on each pageview and a total of four minutes on the site during each visit. There are 269 other websites that are linked to this website. The website speed is good with a load time of 0.33 seconds. Roughly $11 \%$ of visits to the site are referred by search engines.

Table 1 shows the summarization of important features exhibited by the websites of Quran that were analysed in this study in April 2013. The data indicated that almost in all cases there is a big increase in the traffic rank of the websites. Quranexplorer.com has drawn a Top traffic ranking of 34802 with 3549 inbound links. Qurancomplex.org has attained $3^{\text {rd }}$ Top traffic ranking of 120637 with 1778 inbound links, While Mp3quran.com has drawn a Lowest Global traffic ranking of 4650656 among the 8 analysed websites.

Search engines often use the number of inbound links that a website has as one of the most important factors for determining that website's search engine ranking, popularity and importance. That is why Quranflash.com has attained $2^{\text {nd }}$ Top traffic ranking of 37814 with highest 5176 inbound links.

Not only the volume of web traffic is an important feature in determining visibility but also the number of linkages to the website is also important. In this case table 1 shows Mp3quran.com and Allahsquran.com have attracted the less linkages, 13 and 269 respectively. Which is one of reason behind their lowest rank.

Qurancomplex.org top the list where Roughly 25\% of visits to the site are referred by search engines, while quranflash.com has lowest percentage of search engines visitors.

\subsection{WEB ACCESSIBILITY}

It is essential that the web be accessible to people with equal access and equal opportunity to all also with disabilities. An accessible web can also help elderly population and also people with disabilities more actively. 
It is futile to have a website that is difficult to access by users owing to non compliance with the existing standards on accessibility.

\subsection{WEB ACCESSIBILITY GUIDELINES}

A numerous efforts and works for establishing standard Web Accessibility Guidelines are governed by many webgroups and organization separately or in cooperatively with World Wide Web Consortium (W3C). ${ }^{1}$ [n 1997, the World Wide Web Consortium established the Web Accessibility Initiative ${ }^{2}$ and in 1999 the Web Content Accessibility Guidelines (WCAG) 1.0 were finalized as a recommendation. Its primary goal was to promote and achieve Web functionality for people with disabilities. However, following the guidelines (by programmers, designers) make Web content more available to all users, whatever user agent they use (e.g., desktop browser, voice browser, mobile phone, automobile-based personal computer, etc.) or constraints they may be operating under (e.g., noisy surroundings, under- or over-illuminated rooms, in a hands free environment, etc.). Following these guidelines also help people find information on the Web more quickly

The development of any website has to comply with the existing accessibility guidelines

\subsection{WEB ACCESSIBILITY EVALUATION TOOLS}

Web accessibility evaluation tools are software programs or online services that are used to check the website's accessibility level under web accessibility guidelines.

There is a huge number of accessibility tools for commercial purposes or freely available on the web such as Watch Fire Bobby, AChecker, Cynthia Says, EvalAccess etc. Some good free web-based website accessibility evaluation tools are linked in. ${ }^{3}$ These tools are very useful for programmers and designers to determine whether or not their sites follow WCAG. During the design, implementation, and maintenance phases of Web development if these tools are

1 Shawn Lawton Henry, Web Accessibility: Web Standards and Regulatory Compliance.: Friends of Ed, 2006, ISBN: 1590596382.

2 WA - http://www.w3. org/wai.

3 (2011, August) Free Web-Based Web Site 51 Accessibility Evaluation Tools. [Online]. http://usabilitygeek.com/ 10 -free-web-based-web-siteaccessibility-evaluation-tools/ 
used carefully, it can help the targeted users in preventing accessibility barriers, repairing encountered barriers, and improving the overall quality of Web sites. ${ }^{1}$

\subsection{AChecker- A Web Accessibility Software Tool used -:}

AChecker was used to evaluate the eight websites of quran in this research study.

AChecker tool checks single HTML pages for conformance with accessibility standards to ensure the content can be accessed by everyone.This tool is designed to help improve the usability of Web pages.

AChecker produces a report of all accessibility problems for your selected guidelines. AChecker identifies three types of problems:

1. Known problems: These are problems that have been identified with certainty as accessibility barriers. You must modify your page to fix these problems;

2. Likely problems:These are problems that have been identified as probable barriers, but require a human to make a decision. You will likely need to modify your page to fix these problems;

3. Potential problems: These are problems that AChecker cannot identify, that require a human decision. You may have to modify your page for these problems, but in many cases you will just need to confirm that the problem described is not present. $^{2}$

Applying AChecker to the 8 Quranic websites it was found that the website, namely the Altafsir.com, Qtafsir.com and Quranexplorer.com top the list in terms of the most number of errors in their websites. The websites that have the least number of errors are Understandquran.com, Mp3quran.com and Quranflash.com. The Altafsir.com has 223 Known problems with 374 potential problems

The presence of those errors if not repaired will render the websites to be less accessible for the users to navigate.

1 (1994) Evaluating Accessibility. [Online]. http://www.w3. org/WAIIeval/Overview.html.

2 Web Accessibility Checker:

http://achecker.ca/documentation/index.php?p=checker/index.php. 


\begin{tabular}{|l|c|c|c|}
\hline & Problems & Problems & Problems \\
\hline Qurancomplex.org & 32 & 1 & 177 \\
\hline Quranflash.com & 25 & 1 & 108 \\
\hline Understandquran.com & 9 & 1 & 445 \\
\hline Qtafsir.com & 27 & 4 & 725 \\
\hline Quranexplorer.com & 166 & 1 & 523 \\
\hline Altafsir.com & 223 & 2 & 374 \\
\hline Mp3quran.com & 24 & 2 & 45 \\
\hline Allahsquran.com & 39 & 1 & 123 \\
\hline
\end{tabular}

\subsection{CONCLUSION}

This study investigated the Visibility and Content Accessibility of Quran Web Portals by examining eight websites of QURAN in terms of their most web traffic volume, inbound links, country visitors, world ranking, percentage of search engines visitors and the load time for opening the websites.

According to three-month Alexa traffic rankings it was found that Quranexplorer.com is most visible website.Qurancomplex.org has attained 3rd Top traffic ranking, While Mp3quran.com has drawn a lowest global traffic ranking among the 8 analysed websites. Qurancomplex.org top the list in having more percentage of search engines visitors.

Applying AChecker it was found that the most inaccessible website is the Altafsir.com while Qtafsir.com and Quranexplorer.com have large number of errors in their websites.

The findings show that unless barriers to accessibility and visibility are removed then usability of the websites would be compromised. The return on investment for the websites of Quran would be maximally exploited if those prerequisites are given due recognition.

Therefore web developer's responsibility should also include constantly improving the visibility and accessibility of the Web site.

Table: 1

Summarization of important features exhibited by the websites of Quran that were analysed in this study in 2013

\begin{tabular}{|l|c|c|c|c|c|}
\hline Website & Rank & InLinks & Speed & User Countries & Search \% \\
\hline Qurancomplex.org & 120637 & 1778 & 2.988 & KSA,UAE,USA & $25 \%$ \\
\hline Quranflash.com & 37814 & 5176 & 0.875 & Egypt,Sudan,UAE & $10 \%$ \\
\hline
\end{tabular}




\begin{tabular}{|l|c|c|c|l|c|}
\hline Understandquran.com & 198208 & 368 & 2.268 & Pak,USA,India & $14 \%$ \\
\hline Qtafsir.com & 302897 & 371 & 33 & USA,India & $15 \%$ \\
\hline Quranexplorer.com & 34802 & 3549 & 3.844 & USA,Kuwait & $16 \%$ \\
\hline Altafsir.com & 161427 & 1283 & 2.897 & Jordon, UAE & $17 \%$ \\
\hline Mp3quran.com & 4650656 & 13 & 1.385 & Algeria,KSA,UK & $18 \%$ \\
\hline Allahsquran.com & 475065 & 269 & 0.33 & Egypt,USA & $11 \%$ \\
\hline
\end{tabular}

\section{REFERENCES}

ComScore. 61 billion searches conducted worldwide in August. www.comscore.com/press /release.asp?press=1802, 2008.

Wu, B., \& Davison, B.D. (2006, April). Undue influence: Eliminating the impact of link plagiarism on web search rankings. ACM SAC 2006. ACM 1-59593-108-2/06/0004. Dijon, France.

Vaughan, L., Thelwall, M. (2003), "Scholarly use of the web: what are the key inducers of links to journal websites?", Journal of the American Society for Information Science and Technology, Vol. 54 No.1, pp.29-38.

Conway, M., \& Dorner, D. (2004). An evaluation of New Zealand political party websites. Information Research, 9(4), paper 196.

Longe, Heather (2008) The art of web design. Techniques 83(3), p26-33.

Shawn Lawton Henry, Web Accessibility: Web Standards and Regulatory Compliance.: Friends of Ed, 2006, ISBN: 1590596382.

Chartbook on Disability in the U.S. [Online]. http://www. infouse.com/disabilitydataldisabilityll_l.php

(2001, July) Disability as a Function of Age. [Online]. http: //trace. wisc.edu/ docs/function-aging/

(2011, August) Free Web-Based Web Site 51 Accessibility Evaluation Tools. [Online].

http://usabilitygeek.com/ 1 0-free-web-based-web-siteaccessibilityevaluation-tools/

(1994) Evaluating Accessibility. [Online]. http://www.w3. org/WAIIeval/Overview.html

Fan, Weiguo, Schaupp, L. C. and Krishen, A. (2006). Web site success metrics: Addressing the duality of goals. Communications of the ACM, 49(12), P114-117. 
Nielsen, Jacob (2000) How to Conduct a Heuristic Evaluation. Retrieved from http://www.useit.com/papers/heuristic/heuristic evaluation.html on 20 November 2008.

Web Accessibility Checker

http://achecker.ca/documentation/index.php?p=checker/index.php Wikipedia- Alexa Internet - http://en.wikipedia.org/wiki/Alexa_Internet Ahmad Bakeri Abu Bakar (2010) Evaluating the Accessibility and Visibility of Quran-Websites,Information Technology (ITSim), 2010 International Symposium,Print ISBN: 978-1-4244-6715-0

WA - http://www.w3. org/wai. 